doi: 10.15503.onis2021.7.12

\title{
BRAK. EDUKACJA W ZAMĘTACH I ODMĘTACH
}

\author{
Aleksander Kobylarek \\ Uniwersytet Wrocławski, Instytut Pedagogiki, ul. Dawida 1/3, 50-527 Wrocław \\ E-mail: aleksander.kobylarek@gmail.com \\ ORCID:https://orcid.org/0000-0002-4562-9035
}

\begin{abstract}
Abstrakt
Artykuł podejmuje problem redefinicji najważniejszych priorytetów edukacji $\mathrm{w}$ świecie pandemicznym i postpandemicznym. Według autora pandemia obnażyła braki w zakresie wartości naczelnych w obszarze edukacji. Diagnoza sprowadza się do stwierdzenia przeładowania treściami programów kształcenia oraz nadmiernej szczegółowości, która powoduje, że zostały utracone (lub odeszły na dalszy plan) najważniejsze cele edukacji, jakimi są rozwój intelektualny, dbałość o środowisko, trenowanie umiejętności radzenia sobie w życiu. Krótka lista najważniejszych priorytetów zaczyna się od edukacji obywatelskiej, gdyż nieodpowiedzialność jest przyczyną niewłaściwych wyborów w każdej sferze, poprzez kompetencje kluczowe do edukacji ekologicznej. Artykuł podejmuje również problem słabości pedagogiki i wpływu jej niskiej pozycji wśród innych nauk na niedowartościowanie edukacji i rozwoju. Według autora wartość pedagogiki i edukacji w społeczeństwie jest ściśle skorelowana z dobrobytem tego społeczeństwa i jakością życia obywateli.

Słowa kluczowe: pedagogika, kompetencje kluczowe, priorytety edukacji, szkoła

\section{Deficiency. Education in chaos and confusion}

\section{Abstract}

This article deals with the problem of redefining the most important priorities of education in the pandemic and post-pandemic world. According to the author, the pandemic has exposed gaps in the values paramount in the field of education. Diagnosis of the problem comes down to an overloading of educational programs with content and excessive detail, which causes the most important goals of education intellectual development, care for the environment, and training in life skills - to be either lost or relegated to the background. A short list of the most important priorities begins with civic education, because irresponsibility is the reason for wrong choices in every sphere, and on through key competences to environmental education. The article also addresses the problem of the weakness of pedagogy and the impact of its low position among other sciences in the undervaluation of education and development. According to the author, the value of pedagogy and education in society is closely correlated with the prosperity of that society and the quality of life of its citizens.
\end{abstract}


Key words: pedagogy, key competences, educational priorities, school.

Edukacja jest systemem zanurzonym $\mathrm{w}$ innych systemach i harmonizującym się $\mathrm{z}$ nimi nieustannie. Tak więc to, co dzieje się w samej edukacji ma znaczenie dla funkcjonowania gospodarki, polityki i kultury. To zaś, co znajdujemy niejako obok edukacji i czasem nawet pozornie wydaje się być z nią niezwiązane, może mieć znaczenie dla licznych praktyk edukacyjnych (Harari, 2018). Bezpośrednio lub pośrednio.

Poniższe analizy wstępne mają na celu zwrócić uwagę na zagubione/ niejasne/ sprzeczne/ niewłaściwe priorytety edukacji w Polsce i odnoszą się przede wszystkim do zjawisk zaobserwowanych w ostatnich latach. Niektóre z nich są ściśle związane ze zmianami politycznymi ostatnich 6 lat, po uzyskaniu większości w parlamencie przez PIS, ale są tu również opisane takie trendy i zjawiska, które miały miejsce wcześniej i z którymi do tej pory się nie uporaliśmy a niekiedy nawet nie ma woli, żeby się z nimi uporać (Kobylarek, 2021).

Poniższe refleksje wynikają z rozmów, obserwacji rzeczywistości medialnej oraz doświadczeń naukowych i międzynarodowych nabytych podczas realizacji projektów w zakresie edukacji dorosłych. Stąd też podejście zorientowane na edukację nieformalną dorosłych może być przez czytelnika rozpoznane jako dominujące, chociaż refleksje dotyczą wszystkich typów.

\section{EDUKACJA OBYWATELSKA}

Społeczeństwa są mądre mądrością swoich przedstawicieli (Kobylarek, 2019). Lub głupie ich głupotą. W świecie zdominowanym (ilościowo oraz ideowo) przez demokracje to decyzje wyborców przesądzają o sensownym lub bezsensownym przywództwie. Polska póki co jest demokracją przynajmniej dopóki obywatele mają możliwość wyboru. Wydaje się, że wybór między dobrem a złem jest oczywisty. Jednak aby ta oczywistość się zrealizowała musi wystąpić kilka warunków po stronie samych obywateli:

- muszą wierzyć w mechanizmy demokratyczne,

- muszą wiedzieć, co jest właściwe,

- muszą chcieć wybrać właściwie.

Porażki demokracji sprawiaja, że część obywateli nie jest w ogóle przekonana, że ma jakikolwiek wpływ na sposób sprawowania władzy i urządzenie państwaod ministerstw do poziomu lokalnej społeczności (Applebaum, 2020). Niewiara jest w dużej części przyczyną wycofania (choć nie jedyną ani może nawet najważniejszą). I w ten sposób mamy do czynienia z zamkniętym kręgiem, pętlą zaniedbań oraz samospełniającą się prognozą. Demokracja wymaga, żeby ją pielęgnować. Zaniedbana niszczeje i obrasta chwastami $\mathrm{w}$ postaci chciwych, skorumpowanych i aroganckich polityków, dla których dobro wspólne łatwo stanie się łupem, suknem do wydarcia.

Demokracje funkcjonują dobrze, kiedy obywatele interesują się polityką na tyle, by móc ocenić skuteczność swoich wyborów a w przypadku złych wyborów, naprawiają swoje błędy, rozliczając w ten sposób swoich przedstawicieli. Aby przerwać krąg porażki i zamienić go w pętlę doskonalenia demokracji, potrzebny jest systematyczny i regularny udział obywateli w wyłanianiu przedstawicieli władzy (Benda, 1928). 
Edukacja obywatelska w tym zakresie musi się realizować od najwcześniejszych lat i trwać przez całe życie,. Dobry obywatel zaczyna się od odpowiedzialnego za swoje czyny człowieka, który sprząta po sobie, działa zgodnie z przyjętymi powszechnie regułami, przestrzega prawa, udziela się społecznie w organizacjach pozarządowych, daje z siebie otoczeniu więcej niż minimum, które się od niego wymaga w pracy. Dobry obywatel to taki, który wierzy, że świat można uczynić lepszym zaczynając od doskonalenia siebie i dawania właściwego przykładu innym. Taki człowiek będzie również dbał o swoje decyzje i wybory polityczne a ludzie nieuczciwi będą budzić jego odrazę. Skorumpowani politycy nie będą mieli szans działania w takim świecie.

\section{KOMPETENCJE KLUCZOWE}

Wśród wielu grzechów pedagogii ostatnich lat dwa mają szczególne znaczenie.

Po pierwsze praktyka edukacyjna jest przeładowana treściami uznawanymi za konieczne do przyswojenia w edukacji formalnej (Harari, 2018). Stąd też w całej tej szczegółowości i nadmiarze gubimy to, co najważniejsze. Kiedy jest dużo materiału do przyswojenia, liczy się zdanie egzaminu a nie namysł nad sensem wyznaczanych coraz to nowych celów kształcenia. Ludzki umysł ma ograniczoną pojemność a treści nieużywane, których zastosowania uczeń nie zna nawet na etapie nauczania, ulegają szybko zapomnieniu. W ten sposób inwestujemy ogromne pieniądze w edukację, która najdalej po kilku latach od zdania egzaminów ulatuje w niebyt. Warto byłoby więc przemyśleć system edukacji, aby koncentrować się na tym, co najważniejsze i najpotrzebniejsze - aby kompetencje kluczowe znalazły się w centrum, a nie zagubione $\mathrm{w}$ natłoku materiału nauczania, wymieszane $\mathrm{z}$ treściami mniej istotnymi. Struktura całości materiału oraz samego procesu kształcenia budzi uzasadnione wątpliwości.

Drugi problem to postępująca szczególnie po zmianie na stanowisku ministra ideologizacja edukacji formalnej (Kobylarek, 2021). Atmosfera walki ideologicznej i aranżowania treści kształcenia tak, żeby oddawały przekonania liderów partii rządzących, jest nieskuteczna, bo partie u władzy się zmieniają i nie przygotowują odpowiednio do funkcjonowania we współczesnym świecie, bo im więcej treści ideologicznych, tym mniej miejsca w nauczaniu na kompetencje kluczowe. Ideologiczne zadęcie jest mało przydatne $\mathrm{w}$ świecie współczesnym, w którym liczą się przede wszystkim umiejętności pracy z informacja, kompetencje komunikacyjne, pracy w grupie, czy myślenie krytyczne. Ideologia i wiara w narzucany, nieprzeżyty i nie umocniony system wartości, jest przeciwieństwem myślenia krytycznego i umiejętności negocjacyjnych.

Punktem odniesienia dla definiowania zbioru kompetencji kluczowych powinien być świat przyszłości i kształtujący się dopiero co, rynek pracy, który jesteśmy jedynie w stanie w przybliżeniu zdefiniować. Istnieją jednak klasyfikacje, które mogą stać się punktem odniesienia do modelowania istniejącego sytemu edukacji (Kobylarek, Jakubowska, Błaszczyński, 2021). Aby to się stało potrzeba wiedzy o kompetencjach kluczowych, technologii kształcenia i woli politycznej przedstawicieli, których wybiorą mądrzy obywatele. Tym samym wracamy do konieczności kształtowania społeczeństwa obywatelskiego i zamkniętego kręgu błędów lub sukcesów, o czym wspomniałem wcześniej. 


\section{ZNACZENIE PEDAGOGIKI}

Pedagogika jest przez wielu uczonych (nie-pedagogów) traktowana z lekceważeniem. Niektórzy zaliczają ją do tzw. „nauk równoległych”, które są czymś w rodzaju tandetnej podróby, imitacji prawdziwej nauki (Sokal\&Bricmont, 1998). Na korzyść tej tezy mają przemawiać wskaźniki ilościowe i jakościowe, którymi mierzona jest wartość nauki w większej części cywilizowanego świata: index Hirscha, cytowania, wysoko punktowane publikacje, współpraca międzynarodowa, pozyskiwanie finansów dla uczelni w postaci grantów, udział w międzynarodowych projektach badawczych. Tylko nieliczni uczeni zajmujący się pedagogiką mogą wykazać się dużymi osiągnięciami według wymienionych kryteriów (np największe polskie sławy pedagogiczne, praktycznie nie istnieją ani w Scopusie ani Web of Science). Oczywiście zawsze można powiedzieć, że to nie są właściwe wzory odniesienia, ale świat naukowy raczej sprawdza te wskaźniki a nie zapisy w POLONie (polskiej [czyli lokalnej] bazie uczonych $\mathrm{i}$ ich publikacji).

Do tego warto wspomnieć o różnych innych patologiach swoistych dla nauki lokalnej jak:

- mafijne podejście do habilitacji (wątpliwe promowanie na podstawie kryterium towarzyskiego (zob. Śliwerski 2018),

- feudalizm akademicki (Kobylarek, 2017),

- profesorski kompleks Boga (Błaszczyński, 2013),

- poczucie nieomylności władzy/syndrom myślenia grupowego różnych rad doskonałości naukowych, które z samej swojej nazwy już są doskonałe (skoro decydują o doskonałości innych).

Wszystko to powoduje, że jakość uprawianej nauki staje się nie jedynym a jednym $\mathrm{z}$ wielu priorytetów działań w pedagogice, o równym lub (boję się nawet przypuszczać, że) mniejszym znaczeniu niż promowanie osobowości typu bmw (bierny, mierny, wierny). Struktura władzy środowiska naukowego może łatwo zostać wtedy spetryfikowana przez osobowości psychopatyczne, żądne władzy a niezależni myśliciele mogą jeszcze łatwiej zostać zwasalizowani lub w najlepszym przypadku zmarginalizowani. Osobiście znanych mi jest wiele takich przypadków.

W efekcie również i nauka będzie jak te dobrane towarzysko osobowości, bo uczeni bmw będą uprawiać naukę bmw, która znajdzie uznanie nie poprzez publikacje i cytowania w liczących się periodykach, lecz w oczach towarzystwa, które może takich niecytowanych wypromować pomimo ich niewidzialności $w$ świecie nauki. O rudymentarnym postulacie nieposłuszeństwa w myśleniu można zapomnieć.

Tymczasem, aby praktyki edukacyjne były właściwe, wiedza na temat edukacji musi mieć solidne podstawy. Pomimo ścierających się różnych paradygmatów, wiemy jak uczy się człowiek i jak urządzać edukację. Dlaczego więc cały czas mamy z nią problemy i musimy ją (prawie nieustannie) reformować bez końca?

Można przypuszczać, że nie tylko przedstawiciele innych nauk deprecjonują znaczenie nauk o edukacji, wytykając słabość naukową przedstawicieli pedagogiki. Moim zdaniem reprezentanci polityczni również podzielają te negatywne opinie, potwierdzając je czynem szczególnie wtedy, gdy ministerstwa odpowiedzialne za oświatę obsadzane są przez kompletnych ignorantów, niemających wcześniej z edukacją niczego wspólnego. W ten sposób wracamy do mądrego wyboru właściwych 
przedstawicieli, którzy nie będą się kierowali ideologia, butą i arogancją lecz profesjonalizmem i dobrem przyszłych pokoleń. Dopóki jednak takich przedstawicieli nie mamy, to na samych pedagogach ciąży odpowiedzialność, żeby nieustannie wywierać presję na świat polityki. Albo raczej na przedstawicielach środowisk nauczycielskich i naukowych, bo to właśnie ci, jako doradcy naukowi i osoby reprezentujące szersze społeczności, są w stanie mieć jakikolwiek wpływ na urządzanie społeczeństwa przez władzę.

Biorąc pod uwagę zwasalizowanie środowiska i arogancję władzy, można mieć duże wątpliwości, co do skuteczności oporu profesorów i środowisk nauczycielskich. Dodatkowy problem stanowi nie tylko deprecjonowanie pedagogiki jako nauki (tudzież sprowadzanie jej do technologii prymitywnego ideologizowania, jak częściowo czyni to koncepcja „pedagogiki wstydu”) ale antynaukowość obecnego obozu rządzącego w wielu innych obszarach (Reykowski, 2020).

\section{EDUKACJA EKOLOGICZNA}

Za największe wyzwanie edukacyjne naszych czasów uważam zbudowanie świadomości ekologicznej. Przede wszystkim dlatego, że jakiekolwiek inne działania nie mają sensu, jeśli nie uświadomimy sobie, że nasze życie zależy od środowiska, w którym żyjemy. Niedokształceni obywatele, niewłaściwie zdefiniowane priorytety edukacji, nieodpowiedzialni populistyczni politycy, słabi uczeni, niesprawne reprezentacje- wszystko to przyczynia się do przyspieszenia działań antyekologicznych ludzkości i osuwaniu się nas wszystkich w przepaść (Wojciszke\&Rotkiewicz, 2018).

Ignorancja w zakresie ekologii jest poniekąd pochodną antynaukowego podejścia i braków edukacyjnych. Wszystko łączy się w jedną całość (Reykowski, 2020).

Wydaje się też, że stajemy właśnie przed ostatecznym sprawdzianem. Jeśli jesteśmy gatunkiem wystarczająco mądrym, to przetrwamy tę próbę. Jeśli nie przetrwamy, to znaczy, że byliśmy zbyt głupi i zapracowaliśmy sobie na zagładę.

\section{Co Dalej?}

Żeby wyjść z impasu albo raczej wyścigów ku przepaści - ludzkość musiałaby rozpoznać priorytety i zainwestować $\mathrm{w}$ to, na czym się tylko traci ( $\mathrm{w}$ sensie materialnym) - zdrowie i edukację. Demokracje, które postawiły na dobro obywateli są jednak w mniejszości i z pewnością nie są potęgami militarnymi.

W obecnym stanie rzeczy trudno sobie wyobrazić, że nagle ludzkość (lub przynajmniej, ci którzy decydują o jej przyszłości) zmądrzeje i zwróci się ku właściwym priorytetom. Wydaje się to najmniej prawdopodobne.

Niestety najbardziej prawdopodobny jest scenariusz, w którym pogrążeni w waśniach i głupocie, ekspresowo wpadniemy w przepaść.

Istnieje jeszcze inny scenariusz- umiarkowanie optymistyczny. Duża katastro$\mathrm{fa}, \mathrm{w}$ rodzaju uderzenia komety, epidemii lub katastrofy klimatycznej spowoduje takie zniszczenia i śmierć tak wielu osób, że ci, co pozostaną przy życiu, zaczną sobie bardziej cenić takie wartości jako: wspólnotowość, wiedza, mądrość, nauka, natura. 


\section{Bibliografia}

[1] Applebaum, A. (2020). Twilight of Democracy: The Seductive Lure of Authoritarianism. New York: Doubleday Books.

[2] Benda, J. (1928). The Treason of the Intellectuals. New Brunswick and London: Transaction Publishers.

[3] Błaszczyński, K. (2013). Zmierzch bogów - o zasadności likwidacji habilitacji i profesury w Polsce i krajach europejskich [The twilight of the Gods - on the validity of the abolition of habilitation and professorships in Poland and European countries]. Ogrody Nauk i Sztuk(3), pp. 54-63.

[4] Harari, Y. N. (2018). 21 Lessons for the 21st Century. New York: Spiegel \& Grau, Jonathan Cape.

[5] Kobylarek, A. (2017). Nauka sfeudalizowana. O wątpliwych kryteriach oceny osiagnięć naukowych. Ogrody Nauk i Sztuk, 7(7), strony 9-13.

[6] Kobylarek, A. (2019). Education in the post-scientific culture. Journal of Education Culture and Society(1), strony 5-13.

[7] Kobylarek, A. (2021). Post-pandemic challenges for learning communities. Journal of Education, Culture and Society, 12(1), pp. 5-11.

[8] Kobylarek, A., Jakubowska, L., \& Błaszczyński, K. (2021). Potrzeby szkoleniowe w zakresie kompetencji kluczowych osób dorosłych. Andragogy Adult Education and Social Marketing, 1(1).

[9] Reykowski, J. (2020). Disenchantment with Democracy: A Psychological Perspective. Oxford University Press.

[10] Sokal, A., \& Bricmont, J. (1998). Fashionable Nonsense: Postmodern Intellectuals Abuse of Science. New York: Picador.

[11] Śliwerski, B. (2018). Habilitacja. Diagnoza Procedury Etyka Postulaty. Kraków: Impuls.

[12] Wojciszke, B., \& Rotkiewicz, M. (2018). Homo nie całkiem sapiens. Sopot: Smak Słowa. 